\title{
La ciudad como historia interminable Sobre los centros históricos en América Latina
}

\author{
The city as an endless history \\ About historical centers in Latin America
}

Manuel Delgado*

Citar este artículo como: Delgado, M. (2019). La ciudad como historia interminable. Sobre los centros históricos en América Latina. Revista Nodo, 13(26), pp. 97-106

\section{Resumen}

¿Cuál es el criterio que sirve para salvar del tiempo y de la acción humana determinadas zonas de una ciudad a las que se hace merecedoras del título de "históricas"? ¿Cuál es la función del perimetraje de barrios enteros que son promocionados como "interesantes" y que merecen ser rescatados de procesos de decrepitud o marginalización y elevados a la condición de lugares singulares, cuyo valor se traduce en blindaje respecto de cualquier factor que altere o haga peligrar su sosiego? Nos detendremos aquí en las consecuencias, en forma de gentrificación o vaciamiento, de la producción de centros patrimonializados en ciudades latinoamericanas, dinámicas cuyo efecto paradójico es siempre el de los intentos por expulsar de ellos la historia, es decir, el conflicto y la incertidumbre.

Palabras clave: centro histórico, patrimonio, memoria colectiva, centro urbano, gentrificación.

\section{Abstract}

Which is the criterion that serves to save from time and human action certain areas of a city that are worthy of the title of "historical"? What is the function of the delimitation of entire neighborhoods that are promoted as "interesting" and that deserve to be rescued from processes of decrepitude or marginalization and need to be elevated to the status of singular places, whose value translates into armoring with respect to any factor that alters or jeopardize its calmness? We will spot on the consequences, in the form of gentrification or emptying, of the production of patrimonialized centers in Latin American cities, dynamics whose paradoxical effect is always the one which attempts to expel them from history, that is, from conflict and uncertainty.

Key words: historical center, heritage, collective memory, urban center, gentrification.

\section{Introducción}

Se debate con frecuencia a propósito de qué debe entenderse por patrimonio histórico, sobre todo a partir de la evidencia de cómo son puestas sus aplicaciones al servicio de diversas formas de marqueting territorial, predispuesto para vender al mejor precio posible paisajes urbanos a promotores turísticos o inmobiliarios sin demasiados

Fecha de recepción: 17 de febrero de 2019 • Fecha de aceptación: 26 de abril de 2019

\footnotetext{
* Doctor en Antropología y profesor catedrático acreditado de la Universidad de Barcelona. Correo electrónico: manueldelgado@ub.edu
} 
escrúpulos. Cuando se inventarían los elementos humanos distribuidos por el espacio, los trabajos expertos sobre patrimonio, así como las iniciativas políticas al respecto, suelen atender elementos supuestamente ideosincrásicos, nudos o núcleos fuertes que se presumen capaces de remitir a un pasado compartido por una cierta comunidad, rasgos arquitectónicos o urbanísticos que merecen ser resaltados, en detrimento de otros que se desechan o sencillamente pasan desapercibidos. Subrayados en su ubicación y enaltecidos por la mirada del especialista, se considera que esos materiales espaciales a enaltecer expresan elocuentemente virtudes colectivas que deben durar, ingredientes de los que -se insinúa- depende la pervivencia misma de la ciudad que los exhibe como sus atributos extensivos.

Es así que ciertos aspectos del espacio urbano reciben un trato singular al ser listados como patrimonio histórico de un determinado conglomerado urbano. Fragmentos de la forma urbana son de este modo exaltados y protegidos por su valor como testimonio de un pasado valioso; parcelas de la trama de calles y plazas o construcciones pueden aparecer resaltados en los mapas y guías turísticas o en los catálogos expertos indicando la presencia de edificaciones singulares, monumentos característicos o vías reputadas por su pintoresquismo.

Ciertos aspectos del espacio urbano reciben un trato singular al ser listados como patrimonio histórico de un determinado conglomerado urbano. Fragmentos de la forma urbana son de este modo exaltados y protegidos por su valor como testimonio de un pasado valioso.
Y no ya edificios concretos, sino barrios enteros pueden ser enaltecidos por algún factor significativo que los hace dignos de ser recorridos con admiración. Se convierte en museos al aire libre centros urbanos completos y hay ciudades que han sido integramente tematizadas para hacer de ellas polos de atracción para el turismo de masas y el interés inversor. En todos esos casos, no es exactamente el espacio social y lo que contiene o lo que trancurre por y en él lo que se reclama como hablándonos de una determinada sociedad. Se trata más bien de una selección de elementos agudos que se dictamina que pueden resumir una evocación, concretar una adscripción sentimental, sintetizar una identidad o convertirse en simples reclamos para crear oferta de ambiente y paisaje.

Pero, ¿cuál es el criterio que sirve para salvar del tiempo, de la acción humana y, sobre todo, de la depredación inmobiliaria, determinadas zonas de una ciudad, más allá de su valor histórico, artístico o cultural? ¿Cuál es la función del perimetraje de barrios enteros que son promocionados como "interesantes" y que merecen ser "indultados" de procesos de decrepitud o marginalización y elevados a la condición de lugares singulares, cuyo valor se traduce en blindaje respecto de cualquier factor que altere o haga peligrar su sosiego? Nos detendremos aquí en las politicas de generación de centros históricos patrimonializables en ciudades latinoamericanas.

\section{2. ¿Qué es un centro histórico?}

Es a partir de determinado momento que se plantea la necesidad de salvaguardar determinados cascos viejos urbanos del deterioro, pero ante todo de la codicia especulativa resultante de lo que se ha denominado espacialización del capitalismo. Fue para la contención de esas dinámicas de apropiación mercantil de núcleos antiguos que se plantearon las primeras políticas de protección de centros históricos en términos ajenos a los que habían supuesto la generación de meros simulacros históricos "medievales" que habían conocido 
ciertas ciudades en el siglo XIX y principios del XX, como Carcassonne o el Barri Gòtic de Barcelona (Cóccola, 2011). La pionera de lo que se quería que fueran nuevas orientaciones en materia de conservación sería seguramente la de Bolonia, impulsada por su gobierno comunista (Bruschi, 1983). Esta línea -denominada de conservación estructuralserá formalizada en el Congreso de Ámsterdam de 1976 y la "Carta de Venecia", y asumirá como objetivos principales sustraer el patrimonio edificado de las especulaciones del mercado inmobiliario y asegurar el mantenimiento de la actividad social y la población residente en los núcleos urbanos con valor histórico.

Esta nueva sensibilidad se trasladó a América Latina y se concretó en la declaración final del Coloquio sobre la Preservación de los Centros históricos ante el crecimiento de las ciudades contemporáneas latinoamericanas, celebrado en Quito en marzo de 1977. En ese documento se postulaba una definición de centro histórico que remitía a "todos aquellos asentamientos humanos vivos, fuertemente condicionados por una estructura física proveniente del pasado, reconocibles como representativos de la evolución de un pueblo". Se insistía en que "tal formación plantea como uno de los requisitos esenciales de los centros históricos que incluyan un núcleo social y cultural vivo". Semejante acepción descartaba que un centro histórico pudiera devenir un área museificada, es decir una parcela de la ciudad de la que la vida real sistemática y continuada hubiera quedado retirada. Ni siquiera era indispensable que hubiera fragmentos dotados de valor arqueológico o "histórico", es decir relativo a "grandes acontecimientos" del pasado. Lo que verdaderamente hacía reconocible un centro como dotado de valor protegible no era solo la nobleza cultural o artística de sus componentes o del conjunto, sino que estuviera vivo, es decir que tuviera pasado, pero también presente; que allí pudieran percibirse, como en un nicho geológico, los diferentes estratos del desarrollo de una comunidad urbana, el último de los cuales debía estar todavía activo. En las conclusiones de aquel encuentro se convocaba a proteger los centros históricos, pero no de sus habitantes y usuarios, sino de la desfiguración de que podían ser víctimas como consecuencia de actuaciones determinadas "por razones turísticas de coyuntura política o conmemorativa y de catástrofes naturales, aplicando criterios limitados que van desde la conservación de monumentos aislados hasta maquillajes escenográficos" ${ }^{1}$

Han pasado más de ocho lustros y esa definición está muy lejos de haber determinado los criterios que jerarquizan los espacios de una ciudad para destacar alguno como tesoro. La perspectiva experta establece que un centro histórico es un conglomerado monumental a salvaguardar en virtud de ciertos valores abstractos de los que supone que es condensación. Una vez así considerado, el centro estatuado como riqueza cultural se constituye en una especie de área protegida en la que recibe derecho a existir una cierta Verdad que, si no fuera por el recinto reservado en que se la confina, peligraría por causa de los factores depredadores -intereses económicos, apropiaciones prosaicas o el simple paso de los años- que la acechan. Ahora bien, sabemos que esos espacios son seleccionados como contribuciones estratégicas a procesos que suelen ser, al mismo tiempo, de legitimación simbólica de las autoridades políticas que los patrocinan y de promoción en el mercado internacional de ciudades, todo ello en el marco general del ciclo actual de globalización económica, política y cultural.

Detectada la naturaleza última de la acreditación de "autenticidad" de centros históricos como elemento clave al servicio de lógicas generadoras de plusvalías económicas y simbólicas, solo queda reconocer sus efectos sociales, que con tanta frecuencia implican la expulsión de vecinos o usuarios considerados como incompatibles con la "calidad" que se busca obtener de esos núcleos urbanos singularizados. Estos procesos se están produciendo en centros históricos lati-

1 http://ipce.mcu.es/pdfs/1967_Carta_de_QUITO.pdf.. 
noamericanos, objeto de intervenciones que han intentado imitar el modelo europeo de turismo cultural (Gutiérrez, 2009), una forma de continuidad y renovación de las raíces coloniales del urbanismo desarrollado en los países llamados del "tercer mundo" (Porter, 2007). El supuesto objetivo de este tipo de intervenciones ha sido el de preservar esas parcelas urbanas singulares de los desmanes producidos hasta ese momento por intereses económicos que todavía no habían reparado en la industria turística como fuente de beneficios y rescatando lo sobrevivientes de una antihistoricidad de un movimiento moderno que había dejado casi sin edificios antiguos a ciudades como São Paulo o Buenos Aires, por mucho que algunas ciudades - como el caso de Brasilia (Aragão Costa, 2001) - hicieran de su modernidad la base de su singularización. Aunque, en realidad bien podría decirse que los centros proclamados como "históricos" no encarnan el pretérito, como pretenden, sino el porvenir, puesto que lo que hacen es escenografiar un determinado proyecto de lo que las elites quisieran que fueran las ciudades que dominan y administran.

En las ciudades latinoamericanas la función que habían asumido las plazas centrales como núcleos ceremoniales, religiosos, gubernamentales, comerciales, pero también de y para la interacción social, incluyendo aquella en la que se expresaban contenciosos colectivos, se está viendo transformada por su reconversión en espacios disecados a disposición preferentemente del mercado turístico. En todos los casos, la actuación consiste en generar meros circuitos por los que se hace transitar a los forasteros, desconsiderando cualquier elemento humano o urbano ajeno al relato simplificador que narran. Centros históricos como los de Cartagena de Indias, Cuzco, Santa Ana o Antigua Guatemala ya son paradigmas de esa producción de ambientes tematizados para su exhibición turística. A veces, la actuación puede implicar la generación de auténticas impostaciones, como el falso centro del siglo XVII en Santo Domingo.

Para tales finalidades se promueven actuaciones gestoras y urbanísticas cuyo fin es "liberar" los antiguos centros urbanos de lo que se supone que son sus factores de devaluación, siempre derivados - se sostiene- de su "usurpación" por parte de sectores sociales insolventes o problemáticos y por ello indignos de la consideración especial que merecen esos espacios por causa de su valor arquitectónico, histórico o cultural. Entre esos estudios de caso uno de los más conocidos sea el provisto por Setha Low (2000) sobre el Parque Central y la Plaza de la Cultura en San Juan de Costa Rica. Disponemos de un buen número de otras aproximaciones a ejemplos concretos de cuales son las consecuencias sociales de los procesos de patrimonialización, como, por citar algunos, el del centro de Coyoacán, en México DF (Ramírez Kuri 2006), o del de Valparaiso, en Chile, luego de su declaración como patrimonio de la humanidad por la UNESCO (Guerrero Valdebenito 2011).

El barrio de San Roque, en Quito, sería otro caso (Kingman Garcés, 2011), como lo sería también el de la reconversión del de Abasto, en el centro de Buenos Aires, para convertirlo en una especie de parque temático gardeliano (Carman, 2006). Los modelos desarrollados en diversas ciudades mexicanas - Ciudad de México, Puebla, Guadalajara y Monterrey - han sido analizados de manera conjunta desde la perspectiva de la gestión pública (Melé, 1998). También podemos referirnos a excepciones escasas, pero significativas - La

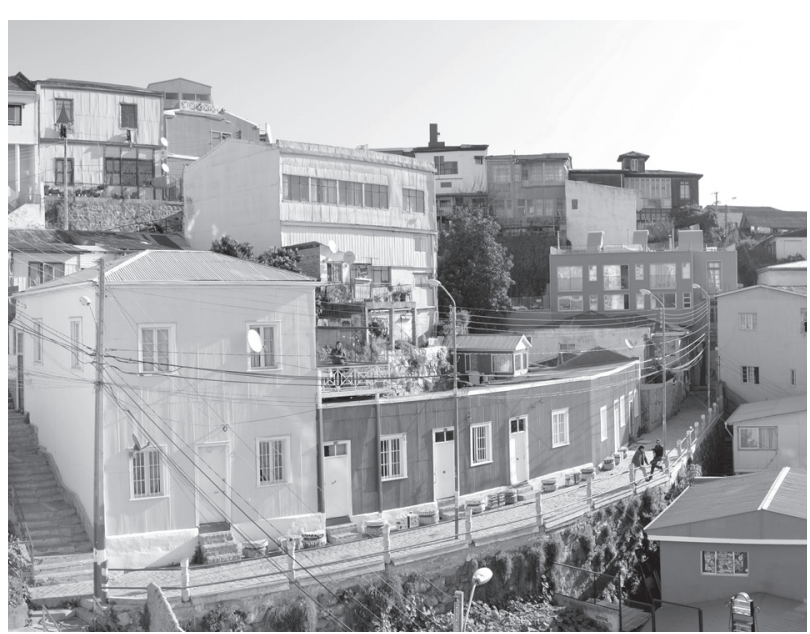

Figura 1. Valparaíso. Fuente: https://pixabay.com/photos/ valparaiso-color-buildings-chile-1803884/ 
Habana Vieja o la Ciudad Vieja de Montevideo-, en las que, acordes con las Normas de Quito y su sensibilidad social, las actuaciones de preservación de centros históricos han sido compatibles e incluso ha animado a la rehabilitación de viviendas populares y el mantenimiento de poblaciones que en otros contextos hubieran sido deportadas, al mismo tiempo que se estimulaba el comercio y se ampliaba las cualidades de versatilidad y heterogeneidad que ya eran características de los lugares intervenidos (Bagnera, 2009). Son solo algunos ejemplos de cómo se ha abordado la pluralidad de acciones y actores involucrados en la reorganización de ciertos núcleos de ciudad como consecuencia de su etiquetado como históricos.

Pero estos últimos casos son ciertamente excepcionales. En el resto de casos, tras los rimbombantes epítetos de "rehabilitación", "higienización", "esponjamiento"..., lo que se oculta o disimula muchas veces es el acoso contra pobres, prostitutas, comerciantes informales, disidentes civiles o cualquier otro elemento que pudiera afear el producto buscado, que no es otro que el de un decorado para prácticas sociales rentables y debidamente monitorizadas. Por ello, en no pocas ciudades, el casco viejo patrimonializado aparece vedado a actos de protesta y fortificado ante su proximidad. Por citar solo ejemplos relativos a tres conjuntos declarados Patrimonio de la Humanidad por la UNESCO, hemos visto que fue el caso de la Plaza Mayor o Plaza San Martín, emplazamiento de las manifestaciones de protesta en Lima, clausurado ante las convocatorias de \#Tomalacalle en julio 2013; el de la Plaza Grande en la ciudad de Quito, cerrada ese mismo verano, a las concentraciones antigubernamentales contra la iniciativa YasuníITT, mientras se permitían las concentraciones de apoyo al gobierno; por último, es también el caso del Zócalo y todo el centro histórico de la capital federal mexicana, que quedó literalmente blindado - placas metálicas protegiendo numerosas fachadas - ante las concentraciones derivadas de las huelgas nacionales de maestros de agosto de 2013 y junio de 2018.
En las ciudades latinoamericanas la función que habían asumido las plazas centrales como núcleos ceremoniales, religiosos, gubernamentales, comerciales, pero también de y para la interacción social, incluyendo aquella en la que se expresaban contenciosos colectivos, se está viendo transformada por su reconversión en espacios disecados a disposición preferentemente del mercado turístico.

Es con tales fines de "pacificación" que se promulgan medidas, normativas o legislaciones que dejan en manos de la policía la garantía última de que el uso -aunque sería más propio decir consumo- de esos espacios se vaya a llevar a cabo sin alteraciones de ningún tipo. Planteándolo con claridad: en la inmensa mayoría de casos, se habla de "revitalización" de cascos históricos, pero no se está pensando en otra cosa que en su reapropiación en clave empresarial. En orden a habilitar esos barrios céntricos rigurosamente vigilados, reservados a vecinos y usuarios considerados "dignos", exclusivos $-\mathrm{y}$ por tanto excluyentes-, lo que se acaba generando es una paradoja insalvable: su enaltecimiento en tanto que "históricos" requiere expulsar antes la historia de ellos. La exaltación de una cierta memoria - real o impostada, pero ante todo coherente y sin fisuras- es, simultáneamente, máquina de olvidar todo aquello que, presente o pasado, desmienta o contradiga la ilusión que se espera suscitar de una identidad que todos 
los segmentos sociales presentes -incluyendo aquellos que mantienen entre sí contenciosos emergentes o crónicos- deben acatar como ecuménica, en principio a nivel local y, si es posible - y esa es su máxima ambición-, universal, si la UNESCO les concede la pertinente homologación.

En efecto, la simplificación y la homogeneización que se persigue de ese espacio exigen que las dinámicas sociales reales -las que hilvanan la vida cotidiana y la historia - hayan quedado como en suspenso, anuladas, contenidas más allá del perímetro de seguridad y contención que se ha levantado a su alrededor. Ha sido enaltecido y puesto entre comillas para mostrarlo como proscenio del consenso y la reconciliación entre sectores sociales con intereses e identidades incompatibles, que asumen - muchas veces por la fuerza - la unificación afectual que supone la realización escenográfica de presuntas certezas históricas o culturales compartidas. Para cumplir su misión sedante, todo centro marcado como histórico en guías o inventarios exige mantener alejada la vida real, con todos sus ingrediente de inestabilidad y desasosiego, incompatibles con la tematización -léase falsificación, simulacro o parodia- de que es objeto ese territorio para su puesta en venta. El espectáculo que las promociones inmobiliarias o turísticas han prometido exige deshacer lo que había sido la frecuente coincidencia entre centro histórico y centro urbano: todo centro proclamado histórico debe dejar de ser, para ello y de inmediato, no solo histórico, es decir escenario de y para el conflicto, sino también propiamente urbano.

\section{El centro histórico como decorado vacío}

La recalificación de centros urbanos en tanto que históricos puede traducirse en oferta residencial en "marcos incomparables", en los que el inquilino o propietario podrá disfrutar de un escenario cargado de prestigio. En algunos casos, tales procesos gentrificadores pueden implicar la destrucción de barrios antiguos considerados no lo suficientemente venerables y su sustitución por edificios de nueva planta destinados a estratos sociales altos, como es el caso de lo que fue Santa Bárbara, hoy Nueva Santa Fe, en Bogotá. El centro de Ciudad de México es otro caso de ello (Hiernaux, 2013; Leal Martínez, 2016; Delgadillo, 2016). En ocasiones, el suplantación de vecindarios puede emplear imágenes tomadas del lenguaje de la colonización, como cuando una coalición de instituciones gubernamentales, entidades bancarias y empresas inmobiliarias llamaron al proceso de reconversión como histórico del casco antiguo de San José de Costa Rica como de "repoblamiento" (Araya Jiménez, 2014, pp. 311-315).

Pero esa reconfiguración como decorado histórico puede implicar no cambios en el perfil de sus habitantes, sino su vaciado al servicio de un modelo de entorno atemperado, previsible y libre de sobresaltos, en el que ya no vive nadie y al que los turistas y la clase media local puede acudir a pasear o de compras. El resultado está a la vista: ciudades-ficción, ciudades pura fachada. El secreto es que tras la fachada no hay secretos. De hecho, no hay nada, como tampoco se espera que lo haya alrededor. En efecto, en torno a los edificios y los monumentos de los centros urbanos en formol se querría que solo hubiera visitantes interesados durante el día, comercios a su servicio, y, claro está, los poderes políticos, económicos y religiosos, que han escogido esos barrios enaltecidos para establecer su domicilio social. De noche, nada.

Esa meta se ha conseguido en Europa. Hay núcleos en los que ya nada queda de lo que un día fuera el casco de las ciudades concéntricas europeas, centros necesariamente llenos, a los que uno podía ir en busca de una cierta "verdad social..., la soberbia plenitud de la realidad" (Barthes, 1991, p. 48). Ni rastro de ello en los Stare Miasto de Cracovia, o en el Gamla Stan de Estocolmo o el Staré Mésto de Praga. Venecia, sin duda, en un extremo. En España, todos los cascos monumentales - Salamanca, Girona, Toledo, Granada...- son hoy ejemplos de ello. En Latinoamérica, ese es ya el 
caso de los centros históricos mencionados y de otros más, como el de Sucre, Quito, Paraty o tantos otros.

En ese tipo de marcos, la patrimonialización de los espacios urbanos, las políticas monumentalizadoras, los esfuerzos por tematizar los escenarios ciudadanos, implican, por fuerza, el amansamiento de ese marco que se le brinda al visitante para la recreación y el ensueño, lo que Víctor Delgadillo (2016, pp. 208-210) ha calificado de "blanqueamieno", refiriéndose a la colonia Juárez de Ciudad de México. Su lógica no es por ello muy distinta de la que organiza y ofrecen los modernos centros comerciales, del que en el fondo no dejan de ser variantes "al natural", islas de ciudad ideal en el seno o en los márgenes de la ciudad real, en las que, sin problemas, bajo la atenta vigilancia de la policía y de guardias jurados, el paseante puede sumergirse en el consumo de pasado, belleza y cultura, pero también, y como de paso, de todo tipo de ofertas de moda y ocio en franquicias de grandes cadenas comerciales. Ese es el caso, por citar uno, del Pelourinho, en Salvador de Bahia, declarada patrimonio de la humanidad por la UNESCO, que es en realidad un shopping center al aire libre (Guimarães de Oliveira, 2019).

Lo que se brinda en un centro histórico-monumental sin habitantes es precisamente una constelación ordenada de elementos que se ha

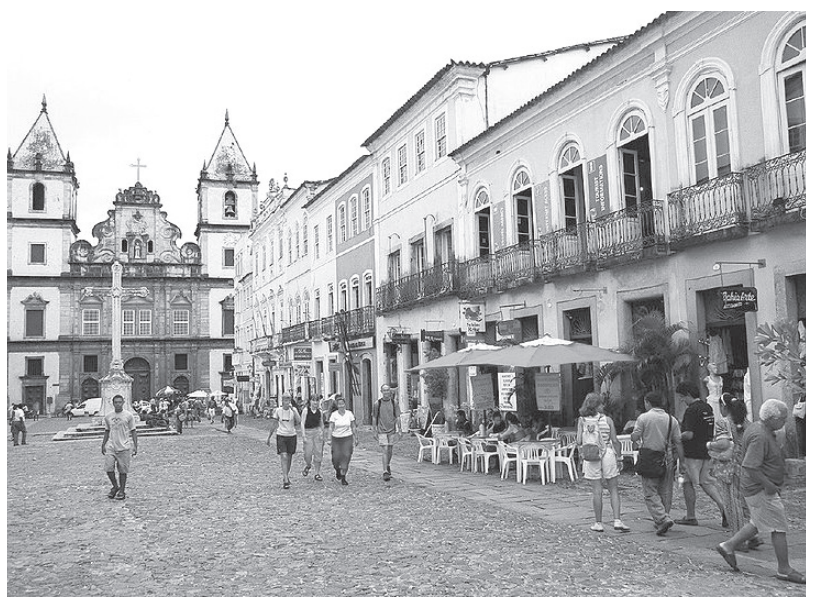

Figura 2. Centro histórico de Pelourinho. Fuente: Bruno Guirin dispuesto como un montaje del que han sido expulsados los esquemas paradójicos y la proliferación de heterogeneidades en que suele consistir la vida urbana en realidad. Desactivado el enmarañamiento, expulsado todo atisbo de complejidad, lo que queda es una puesta en escena que constituye una utopía realizada, es decir, un lugar de ningún sitio, una realidad que no existe de verdad más allá de los límites de su montaje, pero a la que se le concede el deseo de existir bajo la forma de lo que no puede ser más que una mera parodia de perfección. Es utopía, pero también ucronía, puesto que en el fondo hablamos de espacios sin memoria, congelados, expresión de un tiempo fuera del tiempo.

Decorado grandilocuente para la recreación histórica o para todo tipo de liturgias culturales, que sirve a la vez para que las instituciones gubernamentales allí instaladas se bañen en un entorno todo él hecho de nobleza, saber y belleza. En cualquier lugar del mundo, en América Latina también, los centros históricos quieren implicar la versión más institucionalizada de lo que ya era un proceso de zonificación y jerarquización del espacio urbano en términos bipolares: un espacio destinado a lo consuetudinario, a lo empírico, a lo instrumental..., y otro consagrado a tareas de pura representación, espacios para y de los sentimientos, territorios de lo memorable, en este caso de acuerdo con los parámetros de lo que debe resultar rentable y al mismo tiempo emocionante y evocador, generador tanto de capital económico como de capital simbólico (Karaletsou, 1996). El urbanista y el arquitecto se ponen al servicio de ese objetivo en última instancia embalsamador de los centros urbanos catalogados como monumentales. Llevan décadas haciéndolo, contemporaneizando materiales con frecuencia puramente paródicos de la memoria urbana. En una primera fase, mediante la imitación historicista. En una última, mediante la ironización y el pastiche posmodernistas (Pol Méndez, 1999). La coincidencia entre planeadores urbanos, gerentes políticos, gestores culturales y operadores turísticos puede ser total, sobre todo 
El monumentalizador se engaña y pretende engañar al consumidor de grandes pasados, haciéndole creer que en algún sitio -allí mismo, por ejemplo- existen ciudades concluidas, acabadas, cuando se sabe o se adivina que una ciudad viva es una pura formalización ininterrumpida, no-finalista y, por tanto, jamás finalizada. Toda ciudad es, por definición, una historia interminable.

si están en condiciones de entender el significado último de su trabajo. Este no es sino el de ofrecer una imagen cuanto más homogénea mejor del espacio, con el objetivo de ver hecho realidad el encabalgamiento entre urbanización y monumentalización, sueño dorado de integración total entre intereses, espíritu colectivo y participación acrítica en lo diseñado en materia urbana.

Por doquier se comprueban los esfuerzos que unos y otros -del urbanista al promotor turístico, pasando por el político o el empresario que animan y patrocinan a todos ellos- por imponer discursos espaciales y temporales que sometan las dinámicas urbanas reales. El control sobre eso que está ahí y no se detiene -lo urbano, lo que se agita sin cansarse- es lo que todo orden institucionalizado y los intereses privados y privatizadores intentan en sus relaciones con el espacio social. De lo que se trata es de hacerle creer al visitante o al vecino exclusivo lo que estos esperan tener razones para creer, que no es otra cosa que la alucinación de una ciudad plenamente orgánica, imposible si no es a base de inventar y publicitar este principio de identidad que no puede resultar más que de esconder la dimensión perpetuamente alterada de lo que nunca alcanza a ocultar del todo. Frente a la pseudomemoria hecha de clisés y puntos fijos, lo que hay en realidad es otra cosa: las memorias innumerables, las prácticas infinitas, infinitamente reproducidas por una actividad que es a la vez microscópica y magmática.

He ahí el centro histórico ideal, perfecto en el catálogo, en la guía y en el plano, pseudorrealidad dramatizada en que se exhibe la ciudad imposible, dotada de un espíritu en que se resume su historia hecha basílica y palacio, perpetuamente ejemplar en las estatuas de sus héroes, anagrama morfogenético que permanece inalterado e inalterable. Una ciudad protegida de sí misma, es decir, a salvo de lo urbano y de los urbanitas. Lo que podría llegar a ser si se lograse descontarle la informalidad implanificable e improyectable de las prácticas sociales innumerables que el planificador y el promotorprotector de ciudades conocen a medias sin entender nunca del todo. El monumentalizador se engaña y pretende engañar al consumidor de grandes pasados, haciéndole creer que en algún sitio -allí mismo, por ejemplo- existen ciudades concluidas, acabadas, cuando se sabe o se adivina que una ciudad viva es una pura formalización ininterrumpida, no-finalista y, por tanto, jamás finalizada. Toda ciudad es, por definición, una historia interminable.

\section{Referencias bibliográficas}

Álvarez Mora, Alfonso. (2000) "Reforma urbanística o recreación monumental”. En Mireia Viladevall, ed., Ciudad, patrimonio y gestión, Universidad Autónoma de Puebla, Puebla.

Aragão Costa, Anamaria de, 2001. “Tiranías de la singularidad: La búsqueda de la identidad en los proyectos de transformación urbana", en Segundas Jornadas Latinoamericanas de Arquitectura y Urbanismo. Barcelona: Institut Català de Cooperació Iberoamericana, pp. 222-229. 
Araya Jiménez, María del Carmen. (2014) San José, de "París en miniatura" a el malestar en la ciudad. Medios de comunicación e imaginarios urbanos. San José: Editorial Universidad Estatal a Distancia.

Bagnera, Paola. 2008. "Vivienda y espacio público en centros históricos de América Latina”. Perspectivas urbanas, 9 [http://www.etsav.upc.es/ personals/iphs2004/urbper/num09/art09-3. htm; consultado el 13/3/2019].

Barthes, Roland (1991) El imperio de los signos, Madrid, Mondadori.

Bohigas, Oriol. 1997. "La reconstrucció de la ciutat", en Bruno Gabrielli et al., La ciutat histórica dins la ciutat, Ajuntament de Girona, Girona, pp. 159-172.

Cantú Chapa, Rubén. 2000. Centro histórico. Ciudad de México. Medioambiente sociourbano, Ciudad de México: Plaza \& Valdés.

Carman, María. 2006. Las trampas de la cultura. Los "intrusos" y los nuevos usos del barrio de Gardel, Buenos Aires: Paidós.

Ciardini, Francesco y Falini, Paola (eds) (1983), Los centros históricos. Política urbanística y programas de actuación, Barcelona: Gustavo Gili.

Cócola, Agustín (2011) El Barrio Gótico barcelonés. Planificación del pasado e imagen de marca, Barcelona: Madroño.

Del Mármol, Camila; Joan Frigolé y Susana Narotzky, eds., 2010. Los lindes del patrimonio. Consumo y valores del pasado, Barcelona: Institut Català d'Antropologia/Icaria.

Delgadillo, Víctor. (2016) Patrimonio urbano de la ciudad de México. La herencia disputada, Ciudad de México: Universidad Autónoma de la Ciudad de México.

- (2016b) "Selective modernization of Mexico City and its historic center. Gentrification without displacement?",UrbanGeography,2016.[https:// www.tandfonline.com/eprint/RADiwUV4rWIGrknt7uZF/full; consultado 14/3/2019].
Guerrero Valdebenito, Rosa M. (2011) "En nombre del patrimonio. Poder y transformaciones socioterritoriales en la construcción y apropiación social del patrimonio de Valparaíso", en Carmen Guerra de Hoyos, Mariano Pérez y Carlos Tapia, dirs., El Territorio como "demo": demo(a)grafías, demo(a)cracias y epidemias, Sevilla: Universidad Internacional de Andalucía, pp. 300-315.

Guimarães de Oliveira, Ícaro Macedo. (2019) "A nova política urbana para o centro antigo de Salvador-Bahia". En Juliana Marcus et al. (Eds), La ciudad mercancía. Turistificación, renovación urbana y políticas de control del espacio público, Buenos Aires: Instituto de Investigaciones Gino Germani/Observatori d'Antropologia del Conflicte Urbà, pp. 63-86.

Hiernaux, Daniel (2013). “Tensiones socavadas y conflictos abiertos en los Centros Históricos: imaginarios en conflicto sobre la plaza Santo Domingo, Ciudad de México". En Patricia Ramírez Kuri (Ed.), Las disputas por la ciudad. Espacio social y espacio público de Lationamérica y Europa, Ciudad de México: UNAM, pp. 177-198.

Kingman Garcés, Eduardo, dir. 2012. San Roque: indigenas urbanos, seguridad y patrimonio. Quito: FLACSO Ecuador.

Karaletsou, Cleopatra (1996) "La scène de l'ancien et la representation d'une nouvelle composition urbaine: le cas de Xanthi". En Lucien Voyé, dir., Ville et transactions sociales, París : L'Harmattan, pp. 69-82.

Lefebvre, Henri. (1970 [1976]) La revolución urbana, Madrid: Alianza Editorial.

(1974 [2013]) La producción del espacio, Madrid: Capitán Swing.

Leal Martínez, Alejandra (2016), "Gentrificación y nuevas geografías sociales en la Ciudad de México: el caso del centro histórico". En Álvarez Enriquéz, Lucía; Delgado Ramos, Jean Carlo, y Leal Martínez, Alejandra (Eds.). Los desafíos de la ciudad del siglo XXI, Ciudad de México: UNAM, pp. 477-490. 
López Sánchez, Pere. 1986. El centro histórico: Un lugar para el conflicto, Publicacions de la Universitat de Barcelona, Barcelona.

Low, Setha. (2000) On the Plaza: The politics of public space and culture. Austin: University of Texas Press.

Melé, Patrice. (1998) La producción del patrimonio urbano, Ciudad de México: Publicaciones de la Casa Chata, México DF.

Monnet, Jérôme. (2002) "Les dimensions symboliques de la centralité”, Cahiers de Géographie $d u$ Québec, XL/123 (diciembre), pp. 399-418.

Pol Méndez, Francisco. (1999)"Las trazas de la historia como incitaciones a una proyectualidad contemporánea”. En Luis Moya González et al. Vivir las ciudades históricas. Universidad y ciudad histórica. La gestión del patrimonio, Alcalá de Henares: Fundació La Caixa, Ayuntamiento de Alcalá de Henares, Universidad de Alcalá de Henares, pp. 85-97.

Porter, Libby. (2007) Unlearning the Colonial Roots of Planning, Burlington: Ashgate.

Ramírez, Patricia. (2006) "Pensar la ciudad de lugares desde el espacio público de un centro histórico", en Patricia Ramírez y Miguel A. Aguilar, eds., Pensar y habitar la ciudad. Barcelona: Anthropos, pp. 105-129.

Rojas-Mix, Miguel (1978) La plaza mayor. El urbanismo, instrumento de dominio colonial. Barcelona: Muchnik. 